\title{
Sex-Appealing Clothing: Attitudes and Preferences of Young Women in their Ovulation Cycle: An Abstract
}

\author{
Ngoc Pham, Arturo Z. Vasquez-Parraga, and Reto Felix
}

\begin{abstract}
This study investigates the impact of female sex hormones (i.e., luteinizing hormone (LH), estrogen, and progesterone) on women's consumption behaviors on fashion products. Female sex hormones reach peak level when women are near ovulation, and this research examines how these hormones, when at peak level, influence women's attitudes and purchase intention toward sexy and revealing fashion products. The research is based on two theoretical frameworks: ovulatory shift hypothesis (OSH) and theory of reasoned action (TRA). Moreover, moderating effects of sexy fashion consciousness and self-control are investigated. A within-subject survey design was used to examine the proposed phenomenon. Vietnamese women were recruited for this specific study.

In line with $\mathrm{OSH}$, the findings suggest that when near ovulation, women show more favorable attitudes and stronger purchase intentions toward sexy and revealing fashion products. Further, as predicted by TRA, attitudes toward sexy and revealing fashion products mediate the relationship between ovulation and purchase intentions. However, the hypothesized moderating effects of sexy fashion consciousness and self-control were not supported. The results of this study add to related streams of research which suggest that hormonal fluctuations influence consumers' attitudes and purchase intentions. For managers, the results provide suggestions on how to target female consumers for sexy fashion products more effectively.
\end{abstract}

References Available Upon Request

\footnotetext{
N. Pham $(\bowtie)$

City University of New York-Brooklyn College, Brooklyn, NY, USA

e-mail: ngoccindy.pham@brooklyn.cuny.edu
}

\author{
A. Z. Vasquez-Parraga $\cdot$ R. Felix \\ University of Texas Rio Grande Valley, Edinburg, TX, USA \\ e-mail: arturo.vasquez@utrgv.edu; reto.felix@utrgv.edu
}

(C) Academy of Marketing Science 2019 